\title{
Hypoxia signals autophagy in tumor cells via AMPK activity, independent of HIF-1, BNIP3, and BNIP3L
}

\author{
I Papandreou ${ }^{1,4}$, AL Lim $^{1,4}$, K Laderoute $^{2}$ and NC Denko ${ }^{*, 1}$
}

Macroautophagy (called autophagy hereafter) is a catabolic process activated by various types of stress, most notably by nutrient deprivation. The autophagic degradation of intracellular macromolecules provides metabolic support for the cell; however, this physiological process can also initiate a form of cell death (type 2 programmed cell death). Here we report that oxygen deprivation can activate the autophagic pathway in human cancer cell lines. We observed that hypoxia induced distinct cellular changes characteristic of autophagy such as an increase in cytoplasmic acidic vesicles, and processing and cellular localization of microtubule-associated protein-1 light chain 3. Oxygen deprivation-induced autophagy did not require nutrient deprivation, hypoxia-inducible factor-1 (HIF-1) activity, or expression of the HIF-1 target gene BNIP3 (Bcl-2 adenovirus E1a nineteen kilodalton interacting protein 3) or BNIP3L (BNIP3 like protein). Hypoxia-induced autophagy involved the activity of $5^{\prime}$-AMP-activated protein kinase (AMPK). Finally, we determined that cells lacking the autophagy gene ATG5 were unable to activate the autophagic machinery in hypoxia, had decreased oxygen consumption and increased glucose uptake under hypoxia, had increased survival in hypoxic environments, and exhibited accelerated growth as xenografted tumors. Together, these findings suggest that the autophagic degradation of cellular macromolecules contributes to the energetic balance governed by AMPK, and that suppression of autophagy in transformed cells can increase both resistance to hypoxic stress and tumorigenicity.

Cell Death and Differentiation (2008) 15, 1572-1581; doi:10.1038/cdd.2008.84; published online 13 June 2008

Low oxygen tension is a common characteristic of several pathophysiological conditions including cancer. Hypoxia in solid tumors is associated with resistance to radiotherapy and poor prognosis. ${ }^{1}$ One consequence of tumor hypoxia can be cell death. ${ }^{2,3}$ However, several groups have shown that in general tumor cells are well adapted to moderate hypoxia, provided that there are no additional stresses such as glucose deprivation. However, extreme hypoxia is able to activate apoptosis through a hypoxia-inducible factor-1 (HIF-1)-independent process. ${ }^{4-6}$ Interestingly, forced normoxic expression of HIF-1 target gene BNIP3 (Bcl-2 adenovirus E1a nineteen kilodalton interacting protein 3 ) has been reported to cause mitochondrial dysfunction and cell death in some, but not all, experimental settings. ${ }^{5,7,8}$ Recent studies have also implicated BNIP3 in ceramide- and arsenic trioxide-induced autophagy $^{9,10}$ and in a model of ischemia/reperfusion cell death. ${ }^{11}$

$5^{\prime}$-AMP-activated protein kinase (AMPK) is a major regulator of energy homeostasis. ${ }^{12}$ Increases in the AMP/ ATP ratio lead to activation of AMPK, which in turn promotes energy-producing catabolic processes and attenuation of energy-consuming anabolic processes. ${ }^{13}$ One major downstream pathway for this effect is through tuberous sclerosis complex (TSC) and mammalian target of rapamycin (mTOR). ${ }^{14}$ Hypoxia is a potent stimulus of AMPK, which is independent of HIF activity, and can occur even before there are any detectable decreases in intracellular ATP levels. ${ }^{15,16}$ Recent reports suggest that in addition to AMPK's role in regulating normal glycolytic and oxidative metabolism, it can also regulate cellular energy homeostasis through the autophagic recycling of intracellular components. ${ }^{17,18}$

Macroautophagy (called autophagy hereafter) is a catabolic process involving the regulated digestion of cellular macromolecules and even whole organelles. ${ }^{19}$ During autophagy, a portion of the cytoplasm is sequestered in double-membrane vesicles called autophagosomes, which then fuse with vacuoles or lysosomes where hydrolysis of the contents or cargo occurs. ${ }^{20}$ Autophagy was first identified in yeast as a survival mechanism when nutrients were limiting. ${ }^{21}$ Later, it was found that autophagy is necessary for diverse physiological processes in metazoans such as the development of fruiting bodies in Dictyostelium discoideum, key processes in plant metabolism, dauer formation in Caenorhabditis elegans, and for embryonic development and neonatal survival in mammals.

The occurrence of autophagy in solid tumors has been documented; ${ }^{22}$ however, exactly how this process contributes to tumor biology is not clear. Beclin-1, the mammalian homolog of the yeast autophagy gene ATG6, is a haploinsufficient tumor suppressor. Heterozygous deletion of the

${ }^{1}$ Division of Radiation and Cancer Biology, Department of Radiation Oncology, Stanford University School of Medicine, Stanford, CA, USA and ${ }^{2}$ Biosciences Division, SRI International, Menlo Park, CA, USA

*Corresponding author: NC Denko, Division of Radiation and Cancer Biology, Department of Radiation Oncology, Stanford University School of Medicine, Room 1245 CCSR South, 269 Campus Drive, Stanford, CA 94305, USA. Tel: 650724 5066; Fax: 650723 7382; E-mail: ndenko@ @stanford.edu

${ }^{4}$ These authors contributed equally to this work

Keywords: hypoxia; AMPK; BNIP3; respiration; programmed cell death

Abbreviations: AVO, acidic vesicular organelle; HIF-1, hypoxia-inducible factor-1; AMPK, 5'-AMP-activated protein kinase; LC3, microtubule-associated protein-1 light chain 3; MEF, mouse embryo fibroblast; mTOR, mammalian target of rapamycin; TSC, tuberous sclerosis complex; pVHL, von Hippel-Lindau protein

Received 12.3.08; revised 19.5.08; accepted 20.5.08; Edited by N Chandel; published online 13.6.08 
$B E C N 1$ gene was found to decrease autophagy, increase the incidence of spontaneous malignancies, and accelerate the development of HBV-induced neoplasia. ${ }^{23}$ Ectopic re-expression of beclin-1 in human breast cancer cells both increased autophagy and decreased tumorigenicity. ${ }^{24}$ Autophagy has also been shown to protect mammalian cells against metabolic stress: for example, in IL-3-dependent hematopoietic cells ${ }^{25}$ and in immortalized kidney and mammary epithelial cells. ${ }^{26-28}$ However, there is also evidence that autophagy can suppress tumorigenicity through initiation of a type of programmed cell death. ${ }^{29,30}$

The signaling cascades that converge at and activate the autophagic machinery in tumor cells are poorly understood. In the present study, we show that hypoxia is able to activate autophagy even in the presence of nutrients and growth factors in apoptosis-competent cells. Furthermore, this autophagic response is not dependent on HIF signaling, requires ATG5 expression, and is supported by AMPK activity. Autophagy-defective mouse embryo fibroblasts (MEFs) showed decreased mitochondrial activity, increased glucose uptake, and moderately faster growth in vivo. We propose that these metabolic characteristics of autophagydeficient cells contribute to their increased tumorigenicity.

\section{Results}

Oxygen deprivation induces LC3 processing. We first determined whether oxygen deprivation stimulates autophagy, as indicated by the processing of microtubule-associated protein-1 light chain 3 (LC3-I) protein. Autophagic LC3-II has increased electrophoretic mobility and is competent for binding to an autophagosome. ${ }^{31} \mathrm{SiHa}$ and RKO cells were cultured in complete medium for $24 \mathrm{~h}$ under various oxygen concentrations, and cell lysates were analyzed for LC3 mobility (Figure 1a). Oxygen deprivation caused a decrease of the LC3-I form and accumulation of LC3-II, indicative of the induction phase of autophagy. ${ }^{20}$ Note that there was no change in beclin-1 levels in cells exposed to hypoxia (Figure 1a). Next, we detected the accumulation of LC3-II over time (Figure 1b). In SiHa cells, LC3-II accumulation was detectable after $12 \mathrm{~h}$ of oxygen deprivation, whereas in RKO cells, it took $24 \mathrm{~h}$. We also visualized the intracellular distribution of LC3 using a GFP-LC3 fusion protein, as another means to detect autophagic LC3 processing (Figure 1c). SiHa cells were transiently transfected with the GFP-LC3-expressing plasmid and the next day placed under hypoxia for $24 \mathrm{~h}$. These cells were compared to cells incubated in Earle's balanced saline solution (EBSS) for $3 \mathrm{~h}$ of amino-acid deprivation. After treatment, cells were visualized with a fluorescence microscope. Control cells showed diffuse cytoplasmic GFP-LC3 fluorescence, whereas cells subjected to hypoxia or EBSS had distinct foci of GFP-LC3. This pattern was suppressed by the addition of the autophagy inhibitor 3methyladenine $(1 \mathrm{mM})$.

Hypoxia induces the formation of autophagosomes. Autophagy also requires the formation of autophagosomes, which then fuse with endosomes/

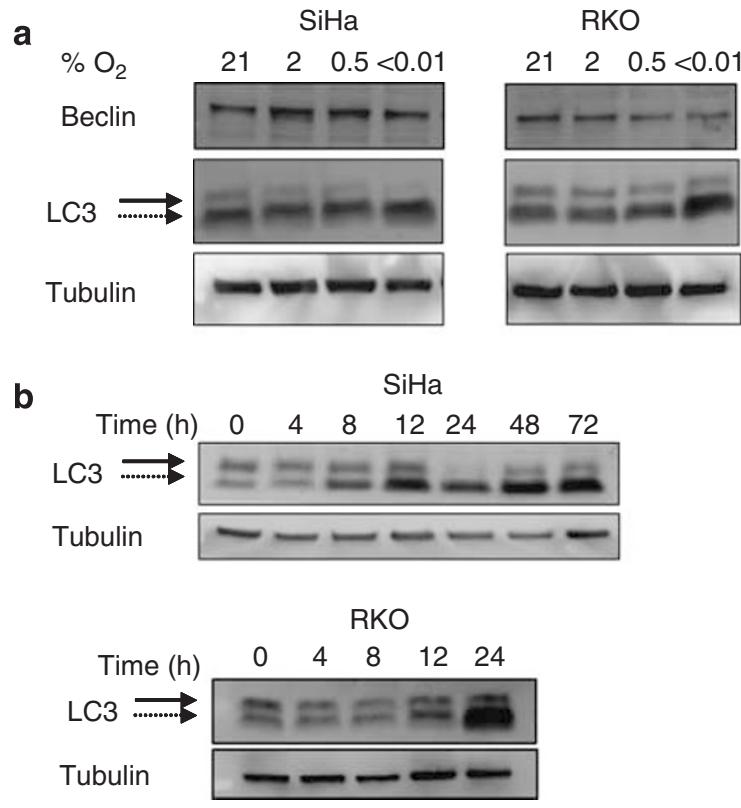

C

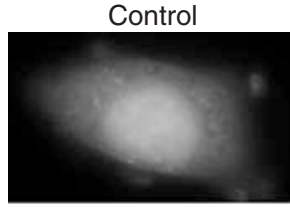

EBSS

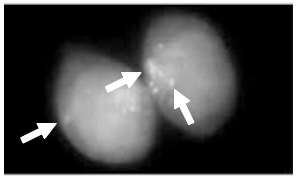

$<0.01 \% \mathrm{O}_{2}$

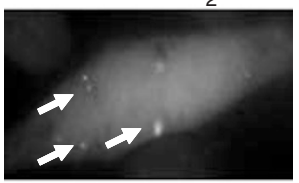

$<0.01 \% \mathrm{O}_{2}+3 \mathrm{MA}$

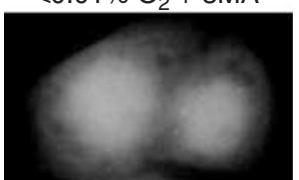

Figure 1 Hypoxia-induced processing of LC3. (a) Cervix carcinoma SiHa and colon carcinoma RKO cells were incubated in decreasing concentrations of $\mathrm{O}_{2}$ for $24 \mathrm{~h}$ and protein lysates were analyzed for beclin-1 and LC3 protein levels. Oxygen deprivation caused a dose-dependent processing of the LC3-I form (solid arrow) to the faster migrating LC3-II form (broken arrow). (b) Time dependency of LC3 processing by severe hypoxia. Cells were incubated in $<0.01 \% \mathrm{O}_{2}$ for the indicated times and samples were analyzed for LC3 levels. Solid arrow indicates LC3-I and broken arrow LC3-II. (c) Photomicrographs showing the intracellular distribution of exogenous LC3 under stress. $\mathrm{SiHa}$ cells were transiently transfected with a GFP-LC3-expressing plasmid, and $24 \mathrm{~h}$ later they were placed under anoxia $\left(<0.01 \% \mathrm{O}_{2}\right.$ ) in the presence or absence of the autophagy inhibitor 3-methyl adenine for $24 \mathrm{~h}$. Samples were fixed and nuclei counterstained with Hoechst 33342 . As a positive control for autophagy activation, one sample was incubated in EBSS for $4 \mathrm{~h}$ before fixation. White arrows indicate characteristic punctate GFP-LC3 staining in the EBSS- and anoxia-treated samples 
lysosomes to form mature acidified autolysosomes (acidic vesicular organelles (AVOs)) where degradation of the cargo occurs. To obtain a quantitative measure of this process, we detected AVO formation with acridine orange (AO) staining. ${ }^{31} \mathrm{AO}$ is a cell-permeable lysosomotropic agent that fluoresces when excited with blue light. In its uncharged state $\mathrm{AO}$ emits green in the cytoplasm and nucleus, and in its protonated form it accumulates inside acidic vesicles and emits red light. We used vital staining with $A O$ and flow cytometric analysis to quantitatively detect AVOs. Incubation of $\mathrm{SiHa}$ cells under hypoxia caused a significant increase in the fraction of cells with high red/low green ratio (Figure $2 a$ ). In addition, hypoxia significantly increased the acidity and/or volume of acidic compartments in RKO colon cancer cells, immortalized MEFs, and the cervical carcinoma cell line HeLa (Figure 2b). The fraction of highly acidic cells under control conditions was $1-3 \%$ of the various cell types, but increased to $20-34 \%$ after exposure to hypoxia. These increases were abolished by the addition of $1 \mathrm{mM}$ 3-methyladenine to the media (data not shown).

We also obtained ultrastructural evidence of oxygen deprivation-induced autophagolysosome formation. SiHa cells were incubated under moderate or severe hypoxia in the absence or presence of 3-methyladenine and cells were processed for evaluation by transmission electron microscopy. Representative electron micrographs shown in Figure $3 c$ demonstrate that autophagosomes were absent in control cells. In contrast, hypoxic cells contained numerous autophagic vacuoles at different stages of maturation including double-membrane encompassed electron-dense structures representing mature autolysosomes with degraded cargo. Quantitative analysis of these images revealed a dose-dependent relationship between the severity of oxygen deprivation and the number of autophagosomes per sectioned cell (Figure 3d). Formation of these structures was inhibited by the addition of 3-methyladenine.

Hypoxia-induced autophagy of tumor cells is independent of HIF-1 and its target gene products BNIP3 and BNIP3L. The transcription factor HIF-1 plays a significant role in the adaptation of cells to hypoxia. ${ }^{32}$ As mentioned above, there is also evidence that autophagic recycling of cytoplasmic components can support cell survival when nutrient availability is limited. Therefore, it was reasonable to investigate whether HIF-1 regulates autophagy induced by oxygen deprivation. To test this hypothesis, we used a panel of genetically matched cell lines with proficient and deficient HIF-1 activity to measure AVO formation under hypoxia. The panel of matched cell lines included SV40 T-antigen-immortalized MEFs, SiHa cells, and MCF-7 breast carcinoma cells. The MEFs were derived from wild-type and HIF-1 $\alpha$ knockout embryos. SiHa and MCF-7 HIF-1 $\alpha$ knockdown cells were established by stable shRNA expression targeted to HIF-1 $\alpha$. The efficiency of the knockdown (shHIF-1 $\alpha$ ) was determined by western blotting for HIF- $1 \alpha$ and its transcriptional target BNIP3. Neither protein was detected in the MCF-7 shHIF-1 $\alpha$ pool, whereas the $\mathrm{SiHa}$ pool showed approximately 70 and $90 \%$ reduction. respectively (Supplementary Figure S1). To test if HIF- $2 \alpha$ contributed to hypoxic autophagy, the panel also included the renal clear cell carcinoma 786-0 cell line in which the HIF-2 $\alpha$ subunit is stabilized due to von Hippel-Lindau protein ( $\mathrm{pVHL}$ ) inactivation, and a clone with re-introduced $\mathrm{pVHL}$ and restored hypoxic regulation of HIF$2 \alpha$. As shown in Figure $3 a$, there was no significant effect of the loss of HIF-1 activity on AVO formation caused by hypoxia. There was variability in AVO formation among the cell lines, but this phenomenon was HIF-1 independent. In agreement with their reported resistance to autophagy, ${ }^{24}$ MCF-7 cells displayed a minimal AVO formation, presumably due to the loss of beclin-1, irrespective of their HIF-1 $\alpha$ and BNIP3 levels. 786-0 cells were also relatively resistant to AVO formation following hypoxia, with only $3-4 \%$ of the cells having a high FL3/FL1 signal ratio. It is noteworthy that stabilization of HIF- $2 \alpha$ expression in $786-0$ cells and, therefore, HIF- $2 \alpha$ activity did not significantly alter the basal levels of autophagy.

These findings demonstrate that HIF-1 activity is not essential for hypoxia-induced autophagy in these diverse cell lines. Nevertheless, recent reports suggest that HIF-1 target BNIP3 is a mediator of autophagy under certain conditions. ${ }^{7,33,34}$ To investigate a possible effect of BNIP3 expression on hypoxia-inducible autophagy independent of its induction by HIF-1, we first examined RKO cell clones that stably overexpress BNIP3, BNIP3L (BNIP3 like protein), or $\mathrm{Bcl}-2$ to evaluate LC3 processing and AVO formation in response to oxygen deprivation. We chose RKO because the BNIP3 gene has been naturally silenced by promoter methylation, ${ }^{35,36}$ so re-expression would be expected to have the greatest possible impact on the processes regulated by the protein. To reveal any possible alterations in LC3 turnover in these cells, we added the cathepsin inhibitors pepstatin A and E64d to the culture media for the final $2 \mathrm{~h}$ before cell harvest. Western blotting confirmed the successful expression of BNIP3L, BNIP3, and Bcl-2 as indicated. In response to hypoxia, there was increased LC3 processing in all the clones equally (Figure $3 b$, left panel). The normoxic and hypoxic number and/or volume of acidic vacuoles was also unchanged by the expression of these proteins (Figure $3 b$, right panel). Taken together, these findings indicate that neither BNIP3 nor BNIP3L is sufficient to induce autophagy. Similar findings were obtained with the expression of these proteins in $\mathrm{HeLa}$ cells (Supplementary Figure S2). In addition, hypoxiainducible autophagy was not inhibited by $\mathrm{Bcl}-2$ overexpression in these tumor cells.

To extend this analysis regarding BNIP3 and BNIP3L, we used RKO cells to perform a complete loss-of-function analysis. In this autophagy-competent cell line without BNIP3 expression, knockdown of BNIP3L would create a cell line deficient in both of these closely related proteins. To this end, RKO cells were stably transfected with an shRNA directed against either nonsense (control) or BNIP3L. Colonies of drug-resistant clones were pooled and left untreated or exposed to hypoxia for $24 \mathrm{~h}$. Cathepsin inhibitors were added to help detect subtle differences in LC3 turnover. Extracts were collected for western blotting (Figure 3c). We found that the RKO cells with shBNIP3L had $90 \%$ reduced expression of BNIP3L in addition to no expression of BNIP3. These pools were then tested and showed proficient AVO formation. Neither BNIP3 nor BNIP3L expression is necessary (or 

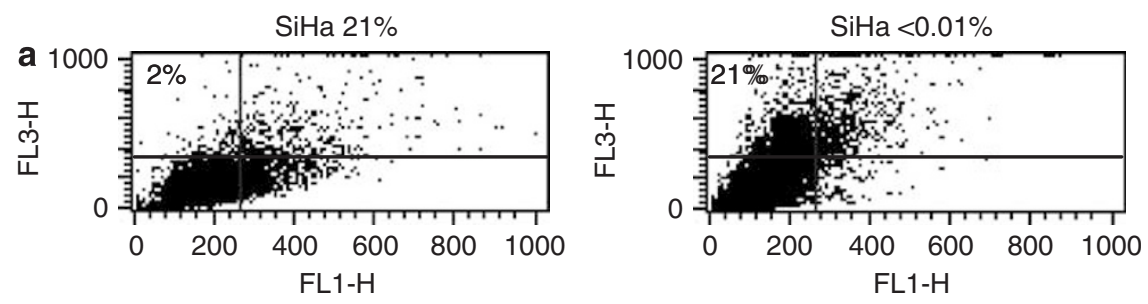

b

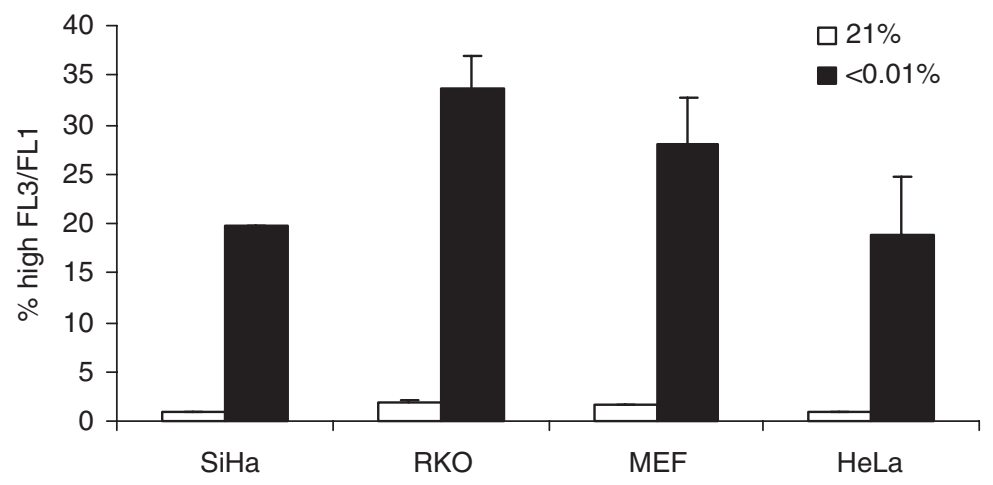

c

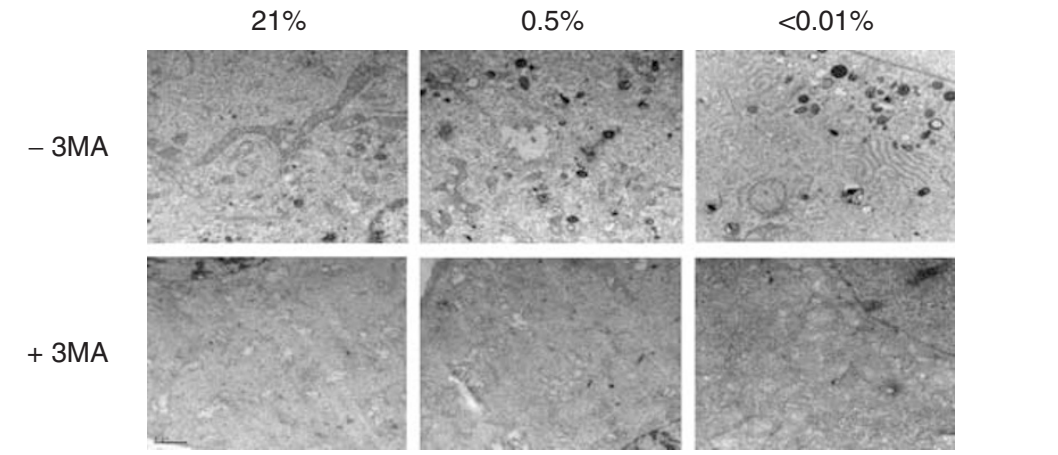

d

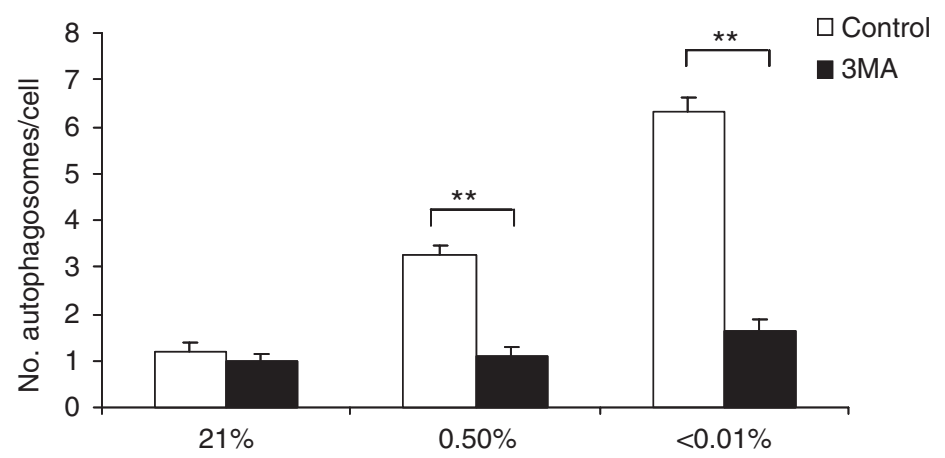

Figure 2 Formation of AVOs under anoxia. (a) Representative plots of AO-stained SiHa samples. Cells were incubated in 21 or $<0.01 \% \mathrm{O}_{2}$ for $24 \mathrm{~h}$, stained with $\mathrm{AO}$, and analyzed by fluorescence-activated cell sorting as described in 'Materials and Methods'. Anoxia caused a significant shift in the red staining intensity compared to green staining. Numbers indicate the percentage of cells with high FL3/FL1 ratio. (b) Quantification of AVO formation. SiHa and HeLa cervical carcinoma, RKO colon carcinoma, and SV40-transformed MEFs were treated, stained, and analyzed as above. Bars represent the average percentage of cells with high red-low green relative staining from three independent experiments, except the SiHa data, which shows the average of two experiments. Error bars: S.E.M. (c) Electron microscope photographs of SiHa cells incubated in the indicated oxygen concentrations for $24 \mathrm{~h}$. Autophagosomal/autolysosomal structures are seen in the hypoxia-treated samples. Their formation is greatly diminished by the addition of $1 \mathrm{mM}$ 3-methyl adenine (3MA). (d) Quantification of autophagosomes under different conditions. The number of autophagosomes per cross-sectioned cell was counted in 12 cells per condition. ${ }^{*} P<0.01 \%$ by Student's $t$-test

sufficient) for the activation of autophagy in response to hypoxia (Figure $3 \mathrm{c}$, middle panel).

We hypothesized that restoring BNIP3 expression in this particular cell line may alter its metabolic response to hypoxia through a change in mitochondrial number/function. Analysis of cells that overexpress BNIP3 or the BNIP3L knockdown cells for mitochondrial oxygen consumption revealed that there was no difference in the previously reported decrease in mitochondrial activity under hypoxia that is mediated by PDK1 (Figure 3c, right panel). ${ }^{37}$ 


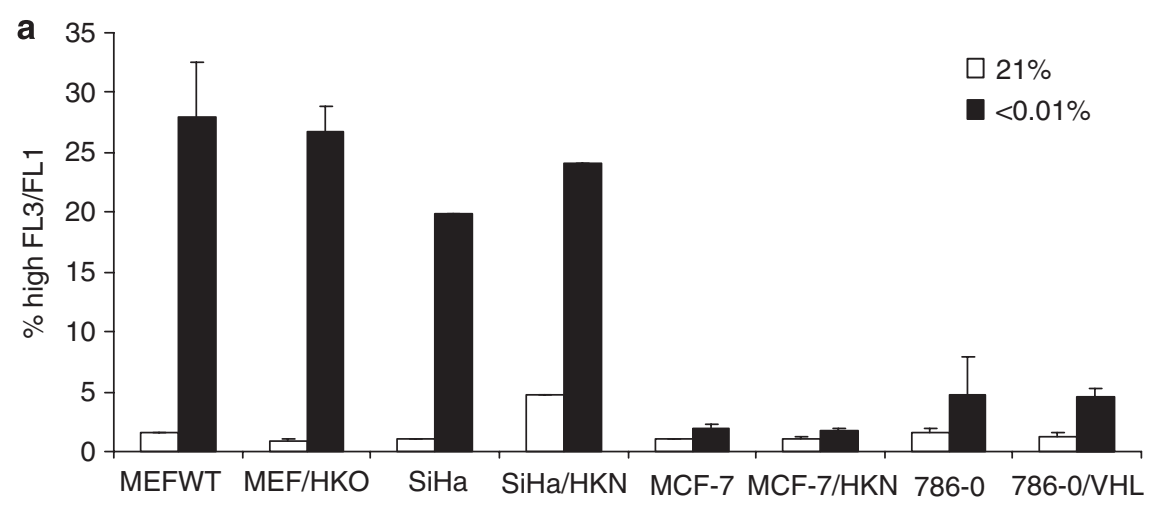

b $\% \mathrm{O}_{2} \quad \frac{\text { Gus }}{21<0.01} \frac{\text { BNIP3 }}{21<0.01} \frac{\text { BNIP3L }}{21<0.01} \frac{\text { BCl2 }}{21<0.01}$

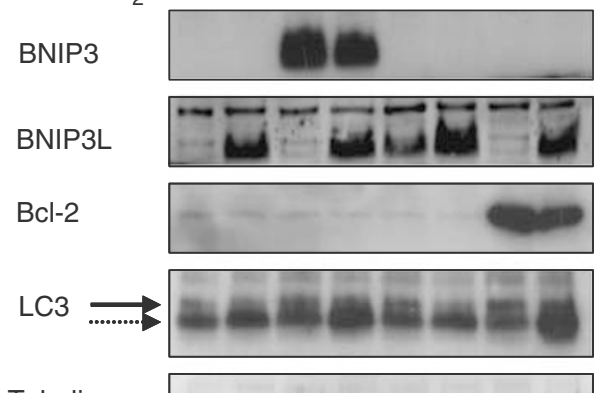

Tubulin
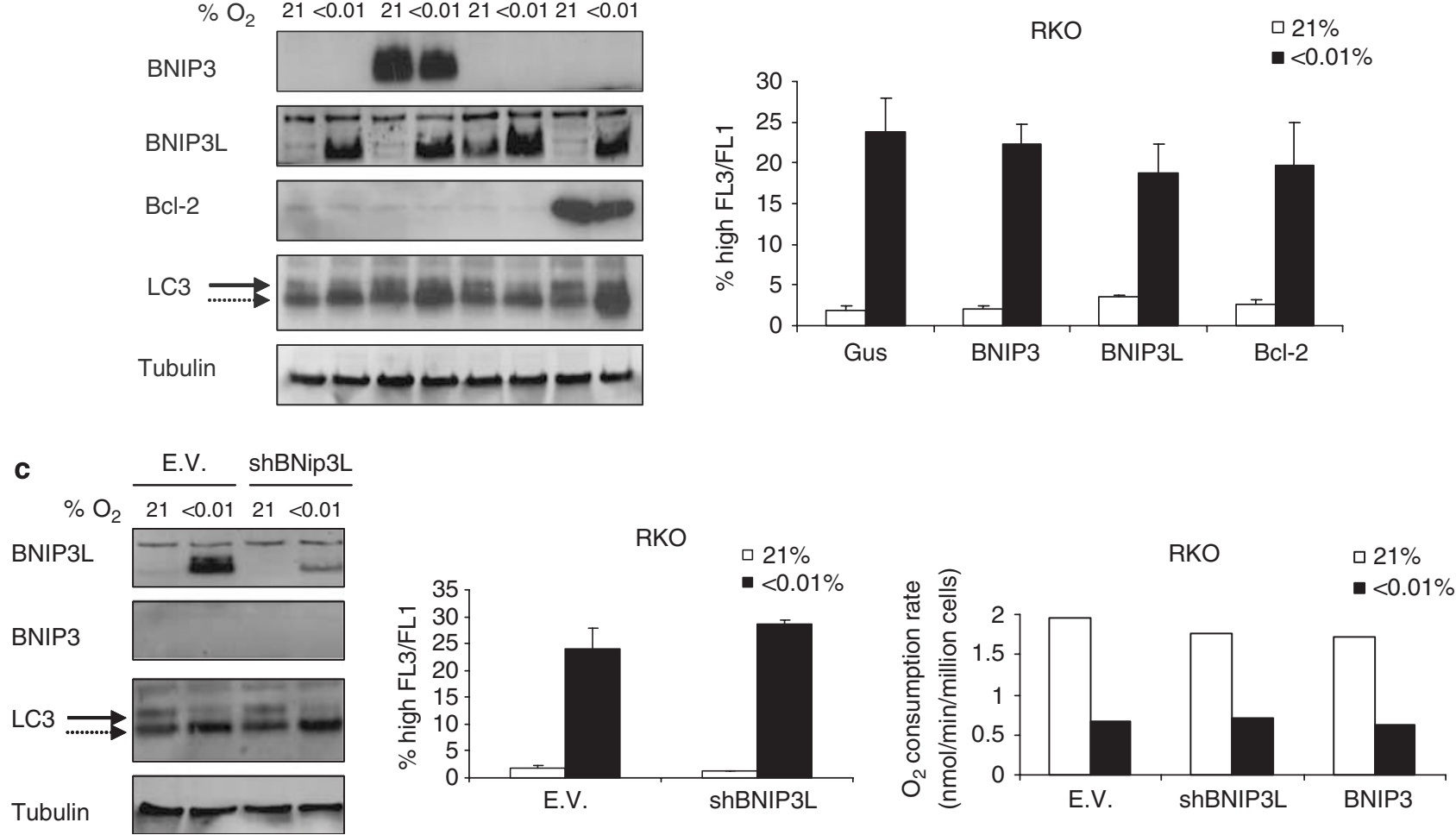

Figure 3 Hypoxia-induced autophagy is independent of HIF-1 and its targets BNIP3 and BNIP3L. (a) Matched HIF-1-proficient and HIF-1-deficient cell lines were analyzed for AVO formation following $24 \mathrm{~h}$ of exposure to $<0.01 \% \mathrm{O}_{2}$. All experiments were repeated between three and seven times, except the experiments using the SiHa clones, which were repeated twice. (b) BNIP3 and BNIP3L are not sufficient to activate autophagy under hypoxia in RKO cells. Pools of clones stably overexpressing BNIP3, BNIP3L, $\mathrm{Bcl}-2$, or the unrelated protein Gus were used. Left panel: Following treatment with normoxia or anoxia in the presence of pepstatin A and E64d, as described in 'Materials and Methods', the protein levels of BNIP3, BNIP3L, BCl-2, LC3-I (solid arrow), LC3-II (broken arrow), and tubulin were determined by immunoblotting. Right panel: Increase in AVO formation detected by AO staining in the different clones after $24 \mathrm{~h}$ exposure to $<0.01 \% \mathrm{O}_{2}$. (c) BNIP3 and BNIP3L are not necessary for hypoxia-activated autophagy. Left panel: Pools of RKO cells transfected with a control plasmid or a short hairpin construct against BNIP3L were treated as described above and protein lysates were analyzed for expression levels of BNIP3L, BNIP3, LC3, and tubulin. Middle panel: Cell suspensions were stained with AO and analyzed by flow cytometry. Right panel: Oxygen consumption rates of control and shBNIP3L- and BNIP3-expressing clones following $24 \mathrm{~h}$ incubation under normoxia or hypoxia

Recent reports indicate that endoplasmic reticulum stress (ER stress; unfolded protein response (UPR)) can activate autophagy. ${ }^{38}$ Severe oxygen deprivation is a known stimulus of UPR; therefore, we investigated whether attenuation of this process could affect hypoxia-induced autophagy. Wild-type, Ire- $1 \alpha^{-1-}$, and PERK ${ }^{-1-}$ immortalized MEFs were exposed to hypoxia for 24 or $48 \mathrm{~h}$, which is adequate to induce ER/UPR. ${ }^{39}$ LC3 processing was detected in all the samples, regardless of their Ire- $1 \alpha$ and PERK status (Supplementary Figure S3). This result indicates that autophagy induced by severe hypoxia is not dependent on a complete UPR stress response.

AMPK activity supports hypoxia-induced autophagy. AMPK is a major regulator of energy homeostasis. ${ }^{12}$ It is activated by many stresses including hypoxia. ${ }^{15}$ Therefore, we investigated the potential role of AMPK in hypoxia-induced autophagy using immortalized MEFs derived from either wild-type or AMPK $\alpha 1 \alpha 2$ knockout embryos. The $\alpha$ subunits, which provide AMPK catalytic 
activity, were absent in these knockout cell lines as assessed by western blotting (Figure 4a). As expected, dose-dependent activation of the AMPK pathway and phosphorylation of acetylCoA carboxylase under hypoxic stress occurred only in the wildtype MEFs (Figure 4a). Incubation of the wild-type cells in EBSS for $3 \mathrm{~h}$ also caused moderate ACC $1 / 2$ phosphorylation. Exposure of the wild-type cells to 0.5 or $<0.01 \%$ oxygen for $24 \mathrm{~h}$ caused significant changes in LC3 protein levels (Figure 4b). Although the rabbit anti-LC3 antibody used in the present study recognized only the higher molecular weight form of LC3, Figure 4b clearly shows that AMPK activity positively regulated both the basal and hypoxia-inducible levels of LC3. In support of the contribution of AMPK to hypoxia-inducible autophagy, its activity was also necessary for maximal AVO formation under moderate or severe oxygen deprivation (Figure $4 \mathrm{~b}$, right panel). To investigate the downstream signaling from AMPK that may be responsible for this autophagy, we examined TSC2 null fibroblasts for their sensitivity to hypoxia because they have elevated mTOR activity. TSC2 null cells showed no significant difference in LC3 processing in hypoxia (Figure 4c, left panel), but significantly lower AVO formation (Figure 4c, right panel). Because TSC2 is activated by AMPK and acts as a negative regulator of mTOR, these results support the hypothesis that AMPK contributes to hypoxia-induced autophagy by downregulating mTOR.

ATG5 is necessary for hypoxia-induced autophagy. The ATG5-ATG12 conjugation system is essential for autophagy triggered by various stimuli. ${ }^{19}$ To investigate whether ATG5 is necessary for hypoxia-inducible autophagy, we used immortalized MEFs from wild-type or ATG5 knockout embryos. Severe oxygen deprivation caused a timedependent accumulation of LC3-II in the wild-type cells, where the ATG5-ATG12 conjugate can be detected, but not in the ATG5 null cells (Figure 5a, left panel). To rule out the

a

\begin{tabular}{|c|c|c|}
\hline AMPK WT & AMPK KO & WT \\
\hline $21 \quad 0.5<0.01$ & & \\
\hline
\end{tabular}

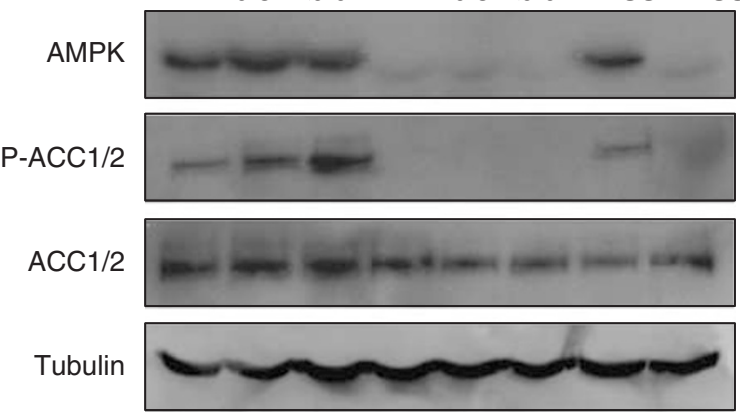

b

$\frac{\text { AMPK WT }}{21 \quad 0.5<0.01} \frac{\text { AMPK KO }}{21} 0.5<0.01$ EBSS $\frac{\text { WT }}{\text { EBSS }}$

LC3

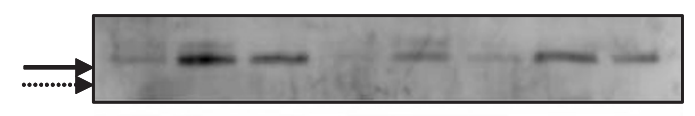

Tubulin
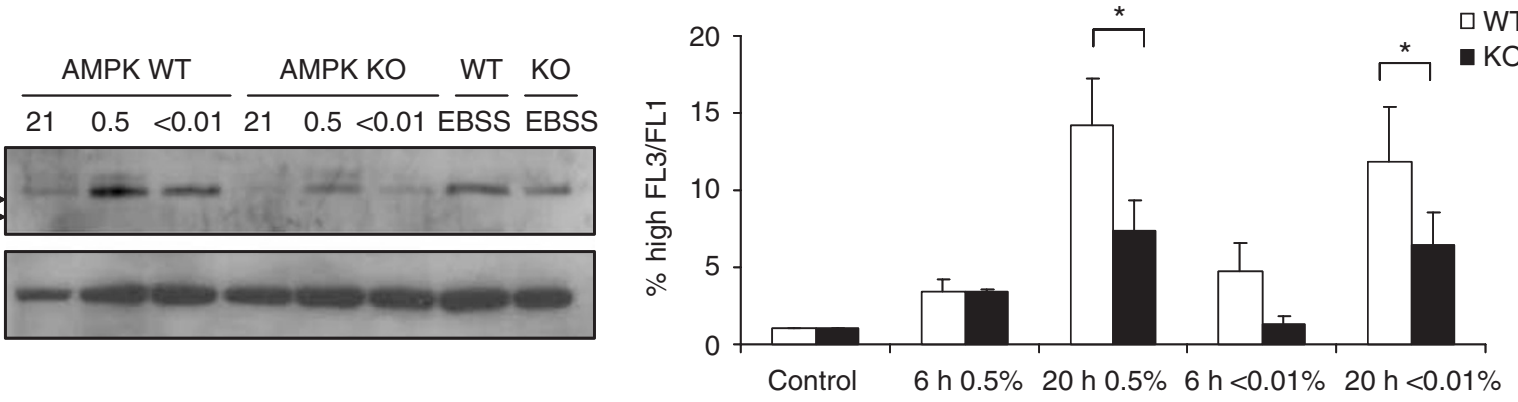

c
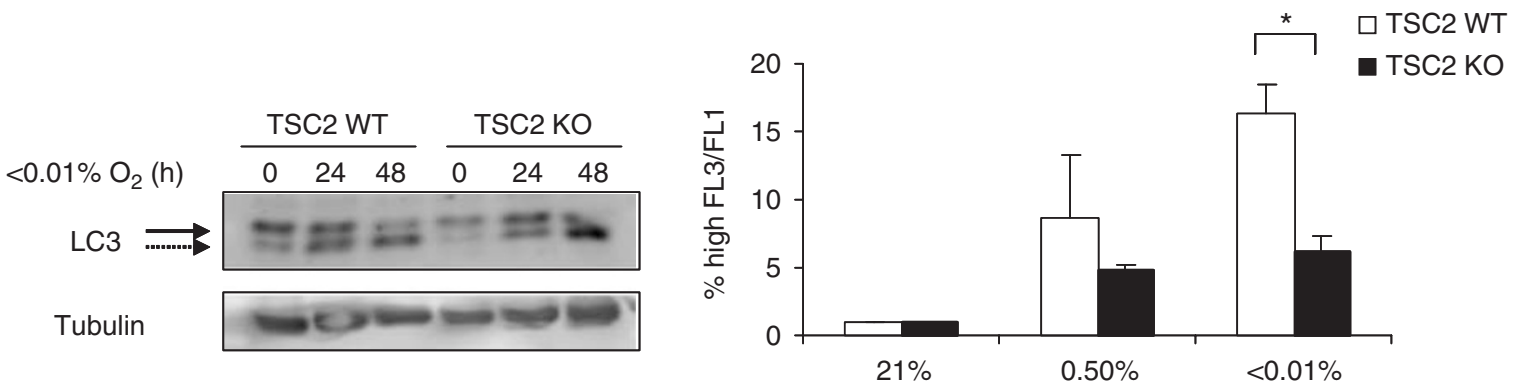

Figure 4 AMPK/TSC2 pathway is involved in hypoxia-induced autophagy. (a) Wild-type (WT) and AMPK $\alpha^{-l-}$ (KO) MEFs were incubated under different $\mathrm{O}_{2}$ concentrations for $6 \mathrm{~h}$ or incubated in Earle's buffered salt solution for $3 \mathrm{~h}$. Activation of the AMPK pathway is detected only in the WT cells. (b) WT and AMPK $\alpha^{-1-}$ MEFs were placed under hypoxia or anoxia for $24 \mathrm{~h}$ or incubated in EBSS for $3 \mathrm{~h}$ and LC3 protein levels were determined by immunoblotting. Only the LC3-I band is detectable (left panel). Quantification of AVO formation under hypoxia in AMPK-proficient and AMPK-deficient MEFs by AO staining (right panel). Plotted is the average of 3-9 independent experiments. (c) TSC2 WT and KO MEFs were placed under severe hypoxia and LC3-I and LC3-II protein levels were determined. The formation of AVO under the indicated conditions was examined by $\mathrm{AO}$ staining. ${ }^{*} P<0.05$ by Student's $t$-test 
possibility of clonal effects, we also tested a tetracyclineregulated ATG5 cell line, which was generated in the immortalized ATG5 $^{-1-}$ MEFs. ${ }^{40}$ Doxycycline treatment of these MEFs resulted in a progressive loss of the ATG5ATG12 band and diminished processing of LC3 during hypoxia (Figure $5 \mathrm{a}$, right panel). These results confirm that ATG5 is necessary for hypoxia-inducible autophagy.

Because AMPK is a critical regulator of metabolism, and ATG5 is downstream of AMPK for hypoxia-inducible autophagy, we next determined if there are any metabolic consequences of autophagy in hypoxic cells. It is known that hypoxia coordinately downregulates the TCA cycle and oxidative phosphorylation and upregulates anaerobic glycolysis. ${ }^{37}$ We hypothesized that autophagic recycling of intracellular components may represent another means of tumor cell adaptation when exposed to hypoxia. Therefore, we performed mitochondrial oxygen consumption measurements on ATG5-proficient and ATG5-deficient cells exposed to moderate $(0.5 \%)$ or severe $(<0.01 \%)$ hypoxia. We found that in agreement with our previous findings, ${ }^{37}$ hypoxia decreased the oxygen consumption rate of both cell types. However, the extent of this inhibition was influenced by the ATG5 status (Figure 5b, left panel). Hypoxic ATG5 null cells showed 33 and $49 \%$ reductions in oxygen consumption rates compared with that of wild-type cells under moderate and severe hypoxia, respectively. Given that the cells were generating less energy from mitochondrial function, it is reasonable that they had increased glycolytic rates. Therefore, we measured glucose uptake in the cells with ${ }^{3} \mathrm{H}$-labeled 2-deoxy-D-glucose (2DG) (Figure 5b, right panel). Compared with wild-type cells, the ATG5 null cells showed a $52 \%$ greater uptake of glucose under both normoxic and hypoxic conditions. Examining lysates from these cells shows increased expression of Glut1 in the ATG5 null cells exposed to hypoxia, presenting a potential mechanism for additional glucose uptake (Supplementary Figure S4).

To determine if these processes that are regulated by ATG5 had a cellular consequence, we tested the ATG5 wild-type and knockout cells for plating efficiency in either moderate or
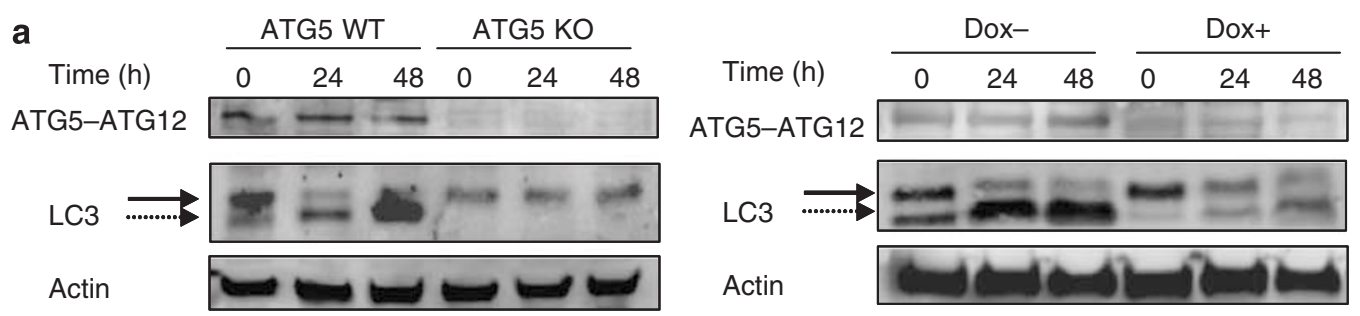

b
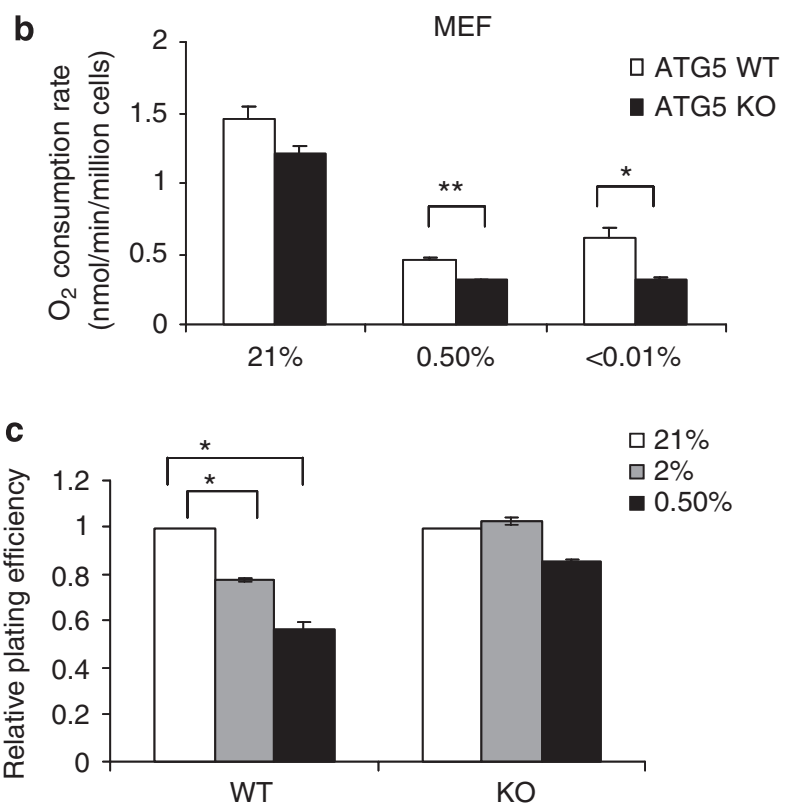
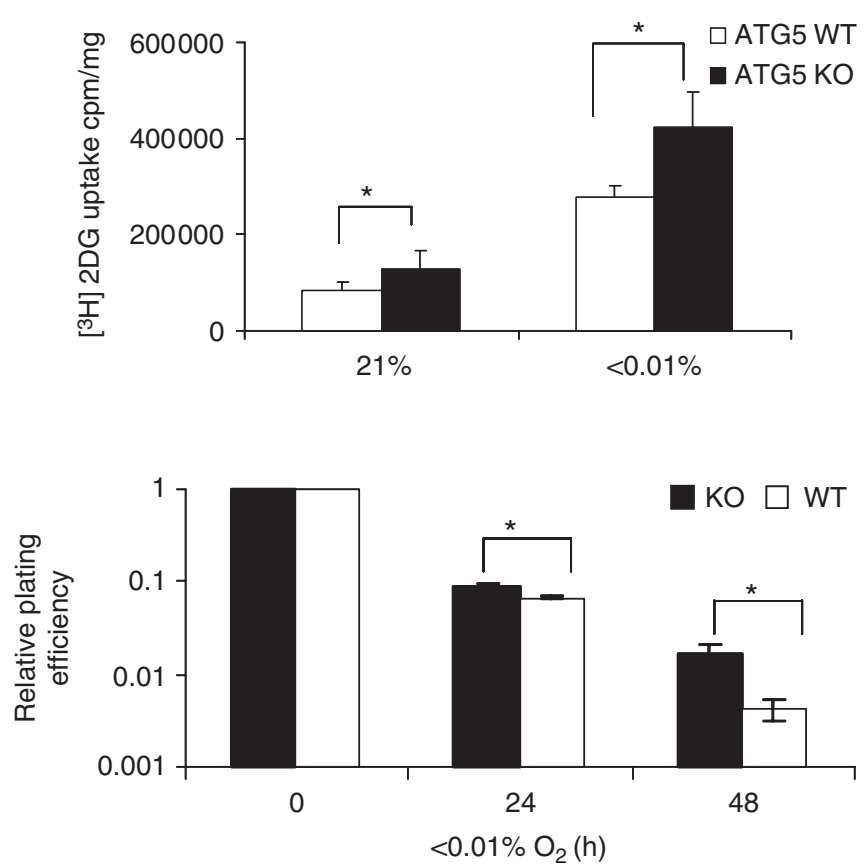

Figure 5 ATG5 is necessary for hypoxia-induced autophagy. (a) LC3 processing under hypoxia is blocked in ATG5-deficient MEFs. The levels of the ATG5-ATG12 conjugate and LC3 were determined by western blot in wild-type (WT) and ATG5 knockout (KO) MEFs (left panel) or MEFs engineered with tetracycline-regulated ATG5 expression (right panel), after incubation in $<0.01 \% \mathrm{O}_{2}$ for the indicated times. Increase of LC3-II (broken arrows) by stress is detected only in ATG5-expressing cells. (b) Effect of autophagy on oxygen consumption and ${ }^{3} \mathrm{H}$-labeled $2 \mathrm{DG}$ uptake under stress. ATG5 WT and KO MEFs were incubated in normoxia or hypoxia for $24 \mathrm{~h}$ and oxygen consumption rates were measured with a Clark-type electrode (left panel). ${ }^{3} \mathrm{H}$-labeled $2 \mathrm{DG}$ uptake after $24 \mathrm{~h}$ growth at 21 or $<0.01 \% \mathrm{O}_{2}$ (right panel). The tracer was added for $30 \mathrm{~min}$ in fresh media with $0.5 \mathrm{mM}$ glucose. (c) Reproductive viability of autophagy-proficient and autophagy-deficient cells under continuous exposure to moderate hypoxia (left panel) or following short exposure to severe hypoxia (right panel). All the experiments were repeated at least three times. ${ }^{*} P<0.05$ and ${ }^{*} P<0.01$ by Student's $t$-test 
severe hypoxia. Single-cell suspensions were plated and grown for 10 days in either 2 or $0.5 \%$ oxygen environments and surviving colonies counted. The wild-type cells showed a significant reduction in plating efficiency in hypoxia when compared to the knockout cells (Figure 5c, left panel). To test the response to severe hypoxia, single-cell suspensions were plated and exposed to $<0 / 01 \%$ oxygen environments for $24-48 \mathrm{~h}$ and then returned to $21 \%$ oxygen environment to allow for colony formation. Again the wild-type cells were moderately more sensitive to severe hypoxia (Figure 5c, right panel).

\section{Autophagy-deficient MEFs are more tumorigenic} in vivo. Impairment of autophagy by loss of beclin-1 has been shown to promote tumorigenesis. Therefore, we tested the ATG5 cells that displayed metabolic and cellular effects to see if suppression of autophagy by ATG5 deletion can accelerate the growth of experimental tumors. ATG5proficient and ATG5-deficient immortalized MEFs were stably transfected with an oncogenic $\mathrm{H}$-ras-encoding plasmid and the resultant transformed cells were injected subcutaneously into nude mice to form fibrosarcomas. The ATG5 knockout cells showed moderately enhanced growth compared to the wild-type cells (Figure 6a). We also made xenograft tumors of the tetracycline-regulated ATG5 cell lines and turned off ATG5 expression by adding $2 \mathrm{mg} / \mathrm{ml}$ doxycycline in drinking water. In agreement with the results obtained using ATG5 null MEFs, conditional loss of ATG5 expression also accelerated the growth of these fibrosarcomas (Figure 6b). At the completion of the studies, some tumors were harvested for determination of their ATG5 and LC3 protein levels (Figure 6c). ATG5 protein was detected only in tumors derived from the wild-type cells and the engineered cell line in the absence of doxycycline. Accordingly, processing of LC3 and accumulation of the LC3-II form were detected only in ATG5-expressing tumors, showing that some level of stress in vivo was capable of inducing autophagy. In contrast, the BNIP3- and BNIP3Lexpressing cells did not show differential growth as xenografts (Supplementary Figure S5).

\section{Discussion}

An increasing list of (patho)-physiological conditions and chemical compounds are recognized for their ability to activate autophagy. Genetic approaches have helped to appreciate the importance of the autophagic machinery during normal development and have sparked interest in the biological consequences of its deregulation in disease, including cancer. Hypoxia, nutrient deprivation, and growth factor depletion represent stresses of the tumor microenvironment that could potently activate autophagy. Our results show that oxygen deprivation can induce autophagy in human tumor cells in the absence of additional stress such as glucose deprivation or serum withdrawal.

Our study showed that the autophagic response does not require an intact HIF pathway, as autophagosome formation was not impaired in HIF- $1 \alpha$ knockout and knockdown cells. We also showed that HIF-2 $\alpha$ is not sufficient to induce autophagy by using the $786-0$ cells that express only this
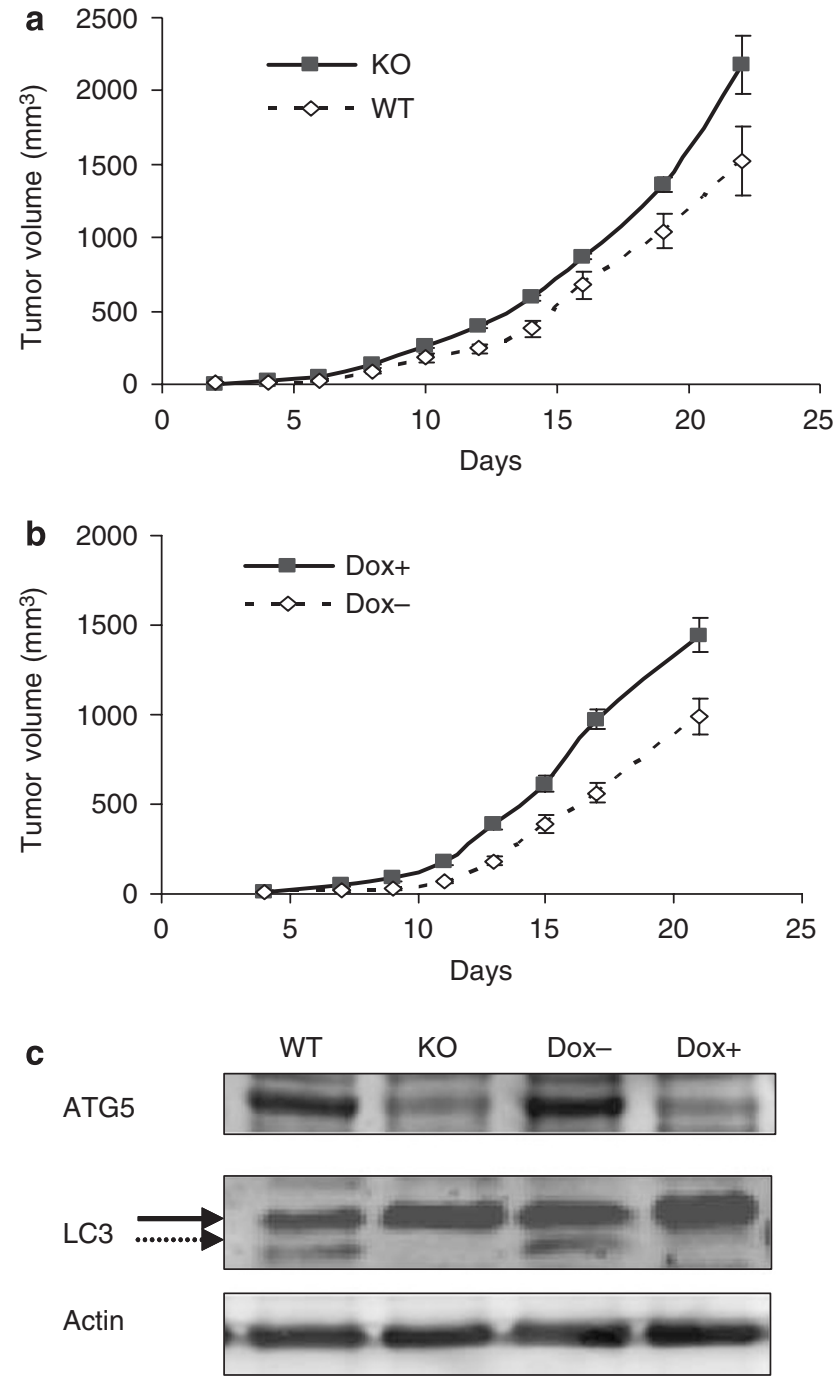

Figure 6 Loss of ATG5 moderately increases the growth of model tumors. (a) Wild-type (WT) and ATG5 knockout (KO) immortalized MEFs were transformed with Ras and were injected subcutaneously into the flanks of female nude mice. Tumor size was measured every 3 days using calipers. (b) Tumor growth curves of Rastransformed MEFs in which ATG5 expression is repressed by doxycycline. Doxycycline was added in drinking water. (c) LC3 processing in vivo requires ATG5. Tumors of the indicated genotypes were isolated and freshly prepared protein lysates were used for immunodetection of ATG5 and LC3. The membrane-bound form of LC3 (broken arrows) is detected only in the lysates of ATG5-expressing tumors

isoform. The results suggest that HIF target genes are not essential for autophagy under hypoxia. This is in agreement with previous findings from our laboratory and others. ${ }^{5,7}$ Several groups have suggested that the HIF-1 target gene BNIP3 mediates autophagy. ${ }^{7,9-11,33,34}$ It is important to note that the above studies utilized different combinations of stress, and the different conclusions demonstrate the complexity of the signaling investigated. Macleod and co-workers ${ }^{7}$ report that in the context of pRb deficiency, BNIP3 is protective against autophagic cell death, but only in the context of $0.5 \%$ oxygen and serum deprivation. Semenza and co-workers ${ }^{34}$ describe how BNIP3 is protective to cells treated with $1 \%$ oxygen, whereas Gibson and co-workers report the 
opposite, ${ }^{33}$ that BNIP3 expression is toxic to cells cultured under $<1 \%$ oxygen. A reasonable explanation for these disparate findings is that several pathways can converge on the autophagic machinery, and various cell systems and stresses rely on these signals differentially. A clear role for BNIP3 in human disease has not been clearly elucidated.

Our results reveal a positive role for the AMPK signaling pathway in the induction of autophagy under hypoxia. There is growing evidence supporting the conserved role of AMPK in autophagy triggered by other stimuli such as entry into stationary phase in yeast and treatment with p53-activating or $\mathrm{Ca}^{2+}$-mobilizing agents. Activation of AMPK has been known to occur after exposure to hypoxia, independently of HIF. ${ }^{15,16}$ Furthermore, the finding that the TSC2 null MEFs are also resistant to hypoxia-induced autophagy suggests that AMPK is working upstream of TSC2 and through mTOR in regulating the process. ${ }^{41}$ The fact that $A M P K \alpha$ nullizygous MEFs were not completely resistant to autophagy raises the possibility of additional pathways converging at the core autophagic machinery.

The complete lack of LC3 processing in ATG5 knockout MEFs indicates that regardless of the upstream triggering signal, ATG5 is necessary for the successful formation of autophagosomes under hypoxia, as it is for other stresses. ${ }^{21,42}$ One important finding of the present study is that ATG5 deficiency alters the metabolic response to hypoxia, namely reduced oxygen consumption and increased glucose uptake. One possible explanation is that hypoxiainduced autophagy provides metabolic substrates for energy production via oxidative phosphorylation. The autophagydeficient cells are lacking this energy source and increase their glucose uptake as a compensatory mechanism. Another, not mutually exclusive, explanation is that autophagy is responsible for the maintenance of a healthy, functional mitochondrial population. The reduced respiration of the ATG5 null MEF could then reflect the accumulation of defective mitochondria. Although the underlying cause of this phenomenon is not clear yet, it is noteworthy that ATG5 deficiency shifts cells toward a more glycolytic phenotype. Increased glycolysis is thought to be advantageous for tumor growth, ${ }^{43}$ so it is tempting to speculate that the increased tumorigenicity of autophagy-defective cells can be somewhat attributed to this metabolic adaptation. This model is not inconsistent with recent evidence that has shown that defects in autophagy render cells susceptible to stress-induced genomic instability and aneuploidy. ${ }^{28}$

\footnotetext{
Materials and Methods

Cell lines and chemicals. HIF- $1 \alpha$ knockout and matched wild-type SV40immortalized MEFs were a gift from R Johnson (University of California, San Diego). ${ }^{44}$ AMPK knockout MEFs have been described elsewhere. ${ }^{15} \mathrm{TSC}^{+1+}$ ${\mathrm{p} 53^{-1-} \text { and TSC2 }}^{-1-} \mathrm{p} 53^{-1-}$ immortalized MEFs were a gift from DJ Kwiatkowski (Harvard, Boston). SiHa cervical and RKO colon carcinoma cells were purchased from the ATCC. Renal clear cell carcinoma $786-0$ and $786-0 / \mathrm{VHL}$ cells were a gift from A Giaccia (Stanford University). HeLa cell clones overexpressing BH3 proteins have been described elsewhere. ${ }^{5}$ Ire-1 and PERK knockout cells were a gift from $A$ Koong (Stanford University). ATG5 knockout, inducible ATG5 MEFs, and LC3 antibody were the kind gift of N Mizushima (Tokyo Medical and Dental University). All cell lines were grown in DMEM with $10 \%$ fetal bovine serum and $20 \mathrm{mM}$ HEPES. Tumorigenic clones were derived from immortalized ATG5
}

wild-type and knockout MEFs by stable transfection with an oncogenic Ha-rasencoding expression plasmid.

For hypoxia treatments, cells were incubated in a humidified hypoxic workstation (Invivo ${ }_{2}$, Ruskinn Inc., Cincinnati, OH, USA) or an anaerobic workstation with a palladium catalyst (Sheldon Corp., Cornelius, OR, USA). Final oxygen concentrations were confirmed using a Clark-type polarographic electrode (Animas, Frazer, PA, USA). In experiments involving inhibition of lysosomal degradation, cells plated in 12-well culture plates were incubated in 21 or $<0.01 \% \mathrm{O}_{2}$ for $22 \mathrm{~h}$, followed by a further $2 \mathrm{~h}$ incubation in fresh equilibrated medium containing $10 \mu \mathrm{g} / \mathrm{ml}$ pepstatin A and $10 \mu \mathrm{g} / \mathrm{ml}$ E64d. All chemicals were purchased from Sigma unless otherwise indicated.

Plasmids. The expression vector pEF2alRESpuro, the sequences targeting HIF-1 $\alpha$, BNIP3, and BNIP3L for knockdown experiments, and the strategy for cloning the sequences into the pSuper vector have been described elsewhere. ${ }^{5,37}$

Western blotting. Cells were lysed in RIPA buffer, sonicated, and protein concentrations calculated by BCA (Pierce, Rockford, IL, USA). Proteins (10-20 $\mu \mathrm{g}$ ) were separated in Tris-Tricine gels and transferred onto Hybond-P membranes (Amersham, Piscataway, NJ, USA). The antibodies used were mouse anti-HIF-1 $\alpha$ (BD Transduction Laboratories, San Diego, CA, USA), anti-LC3 rabbit polyclonal (MBL International, Woburn, MA, USA), mouse anti-beclin-1 (BD Transduction Laboratories), mouse anti-ATG5 (Abnova), chicken anti-ATG5 (Abcam, Cambridge, MA, USA), mouse anti-tubulin (Santa Cruz Biotechnology, Santa Cruz, CA, USA), rabbit anti-Glut1 (Neomarkers, Freemont, CA, USA), mouse anti-GAPDH (Research Diagnostics, Concord, MA, USA), and goat anti-LDH A (Santa Cruz Biotechnology). Rabbit anti-AMPK, anti-ACC, and anti-phospho-ACC antibodies were purchased from Cell Signaling (Danvers, MA, USA). The rabbit polyclonal antibodies against BNIP3 and BNIP3L have been described elsewhere. ${ }^{5}$ Secondary alkaline phosphatase-conjugated antibodies were from Vector Laboratories Inc. (Burlingame, CA, USA). Immunoblotting signals were visualized with the ECF substrate (Amersham) and detected using a Storm Imager (Molecular Dynamics, Sunnyvale, CA, USA).

Immunofluorescence. Cells plated in eight-chamber slides (Nunc) were transfected with a GFP-LC3 expression plasmid using Lipofectamine2000 (Invitrogen, Carlsbad, CA, USA). Cells were fixed with $4 \%$ paraformaldehyde and the nuclei were counterstained with $10 \mu \mathrm{g} / \mathrm{ml}$ Hoechst 33342 . Cells were visualized on a Nikon Eclipse E800 microscope equipped with a Spot RT Slider CCD digital camera (Diagnostic Instruments, Sterling Heights, MI, USA).

AO staining. Changes in intracellular acidic compartments were determined according to Klionsky ${ }^{20}$ with minor modifications. Briefly, following treatment, cells were stained with $2.5 \mu \mathrm{g} / \mathrm{ml} \mathrm{AO}$ for $15 \mathrm{~min}$, trypsinized, resuspended in PBS, and immediately analyzed in a FACSCalibur flow cytometer (Becton Dickinson, San Jose, CA, USA). Green and red fluorescences were measured on a linear scale using the FL1 and FL3 channels, respectively.

Oxygen consumption measurements. Cells plated in 100-mm tissue culture plates were incubated at 0.5 or $<0.01 \% \mathrm{O}_{2}$ for $24 \mathrm{~h}$. They were then trypsinized, resuspended in fresh culture media at $5 \times 10^{6} \mathrm{cell} / \mathrm{s} / \mathrm{ml}$, and oxygen consumption was measured using an Oxytherm electrode unit (Hansatech, Norfolk, UK).

2DG uptake. 2-[1,2,- $\left.{ }^{3} \mathrm{H}(\mathrm{M})\right]$-Deoxy-D-glucose was purchased from PerkinElmer (Boston, MA, USA). Cells in six-well plates were incubated at $37^{\circ} \mathrm{C}$ under $21 \%$ or $<0.01 \% \mathrm{O}_{2}$ for $24 \mathrm{~h}$ in DMEM containing $25 \mathrm{mM}$ glucose, washed twice with PBS, and then fresh medium containing $0.5 \mathrm{mM}$ glucose and $0.5 \mu \mathrm{Ci}^{3} \mathrm{H}$-labeled $2 \mathrm{DG}$ was added for an additional $30 \mathrm{~min}$. The cells were then washed twice with cold PBS and lysed with $0.2 \mathrm{M} \mathrm{NaOH} / 0.1 \%$ SDS. Radioactivity was measured with a liquid scintillation counter. Identical series of samples were lysed in RIPA buffer to measure protein concentrations.

Transmission electron microscopy. Cell monolayers were fixed in $2 \%$ glutaraldehyde buffer. Sections were stained with uranyl acetate and lead citrate, and examined with a Jeoll230 transmission electron microscope. 
Acknowledgements. We are grateful to N Mizushima, D Kwiatkowski, and A Koong for cell lines and reagents. This work was funded by the $\mathrm{NCl}$ (NCD).

1. Vaupel $P$, Mayer A. Hypoxia in cancer: significance and impact on clinical outcome. Cancer Metastasis Rev 2007; 26: 225-239.

2. Evans SM, Hahn SM, Magarelli DP, Koch CJ. Hypoxic heterogeneity in human tumors: EF5 binding, vasculature, necrosis, and proliferation. Am J Clin Oncol 2001; 24: 467-472.

3. Hockel M, Schlenger K, Hockel S, Vaupel P. Hypoxic cervical cancers with low apoptotic index are highly aggressive. Cancer Res 1999; 59: 4525-4528.

4. Brunelle JK, Shroff EH, Perlman H, Strasser A, Moraes CT, Flavell RA et al. Loss of Mcl-1 protein and inhibition of electron transport chain together induce anoxic cell death. $\mathrm{Mol} \mathrm{Cell}$ Biol 2007; 27: 1222-1235.

5. Papandreou I, Krishna C, Kaper F, Cai D, Giaccia AJ, Denko NC. Anoxia is necessary for tumor cell toxicity caused by a low-oxygen environment. Cancer Res 2005; 65: 3171-3178.

6. Santore MT, McClintock DS, Lee VY, Budinger GR, Chandel NS. Anoxia-induced apoptosis occurs through a mitochondria-dependent pathway in lung epithelial cells. $A m$ J Physiol Lung Cell Mol Physiol 2002; 282: L727-L734.

7. Tracy K, Dibling BC, Spike BT, Knabb JR, Schumacker P, Macleod KF. BNIP3 is an $\mathrm{RB} / \mathrm{E} 2 \mathrm{~F}$ target gene required for hypoxia-induced autophagy. Mol Cell Biol 2007; 27 6229-6242.

8. Vande Velde C, Cizeau J, Dubik D, Alimonti J, Brown T, Israels S et al. BNIP3 and genetic control of necrosis-like cell death through the mitochondrial permeability transition pore. $\mathrm{Mol}$ Cell Biol 2000; 20: 5454-5468.

9. Daido S, Kanzawa T, Yamamoto A, Takeuchi H, Kondo Y, Kondo S. Pivotal role of the cell death factor BNIP3 in ceramide-induced autophagic cell death in malignant glioma cells. Cancer Res 2004; 64: 4286-4293.

10. Kanzawa T, Zhang L, Xiao L, Germano IM, Kondo Y, Kondo S. Arsenic trioxide induces autophagic cell death in malignant glioma cells by upregulation of mitochondrial cell death protein BNIP3. Oncogene 2005; 24: 980-991.

11. Hamacher-Brady A, Brady NR, Logue SE, Sayen MR, Jinno M, Kirshenbaum LA et al. Response to myocardial ischemia/reperfusion injury involves Bnip3 and autophagy. Cell Death Differ 2007; 14: 146-157.

12. Hardie DG. AMP-activated/SNF1 protein kinases: conserved guardians of cellular energy Nat Rev Mol Cell Biol 2007; 8: 774-785.

13. Hardie DG. Minireview: the AMP-activated protein kinase cascade: the key sensor of cellular energy status. Endocrinology 2003; 144: 5179-5183.

14. Kwiatkowski DJ, Manning BD. Tuberous sclerosis: a GAP at the crossroads of multiple signaling pathways. Hum Mol Genet 2005; 14 (Spec No. 2) R251-R258.

15. Laderoute KR, Amin K, Calaoagan JM, Knapp M, Le T, Orduna J et al. 5'-AMP-activated protein kinase (AMPK) is induced by low-oxygen and glucose deprivation conditions found in solid-tumor microenvironments. Mol Cell Biol 2006; 26: 5336-5347.

16. Liu L, Cash TP, Jones RG, Keith B, Thompson CB, Simon MC. Hypoxia-induced energy stress regulates mRNA translation and cell growth. Mol Cell 2006; 21: 521-531.

17. Matsui $Y$, Takagi $H, Q u X$, Abdellatif M, Sakoda H, Asano T et al. Distinct roles of autophagy in the heart during ischemia and reperfusion: roles of AMP-activated protein kinase and Beclin 1 in mediating autophagy. Circ Res 2007; 100: 914-922.

18. Meley D, Bauvy C, Houben-Weerts JH, Dubbelhuis PF, Helmond MT, Codogno $P$ et al. AMP-activated protein kinase and the regulation of autophagic proteolysis. $\mathrm{J} \mathrm{Biol} \mathrm{Chem}$ 2006; 281: 34870-34879.

19. Maiuri MC, Zalckvar E, Kimchi A, Kroemer G. Self-eating and self-killing: crosstalk between autophagy and apoptosis. Nat Rev Mol Cell Biol 2007; 8: 741-752.

20. Klionsky DJ. Autophagy: from phenomenology to molecular understanding in less than a decade. Nat Rev Mol Cell Biol 2007; 8: 931-937.

21. Mizushima N, Noda T, Yoshimori T, Tanaka Y, Ishii T, George MD et al. A protein conjugation system essential for autophagy. Nature 1998; 395: 395-398.

22. Liang J, Shao SH, Xu ZX. Hennessy B, Ding Z, Larrea M et al. The energy sensing LKB1-AMPK pathway regulates $\mathrm{p27}$ (kip1) phosphorylation mediating the decision to enter autophagy or apoptosis. Nat Cell Biol 2007; 9: 218-224.
23. Yue Z, Jin S, Yang C, Levine AJ, Heintz N. Beclin 1, an autophagy gene essential for early embryonic development, is a haploinsufficient tumor suppressor. Proc Natl Acad Sci USA 2003; 100: 15077-15082.

24. Liang XH, Jackson S, Seaman M, Brown $\mathrm{K}$, Kempkes B, Hibshoosh $\mathrm{H}$ et al. Induction of autophagy and inhibition of tumorigenesis by beclin 1. Nature 1999; 402: 672-676

25. Lum JJ, Bauer DE, Kong M, Harris MH, Li C, Lindsten T et al. Growth factor regulation of autophagy and cell survival in the absence of apoptosis. Cell 2005; 120: 237-248.

26. Degenhardt K, Mathew R, Beaudoin B, Bray K, Anderson D, Chen G et al. Autophagy promotes tumor cell survival and restricts necrosis, inflammation, and tumorigenesis. Cancer Cell 2006; 10: 51-64.

27. Karantza-Wadsworth V, Patel S, Kravchuk O, Chen G, Mathew R, Jin S et al. Autophagy mitigates metabolic stress and genome damage in mammary tumorigenesis. Genes Dev 2007; 21: 1621-1635.

28. Mathew R, Kongara S, Beaudoin B, Karp CM, Bray K, Degenhardt K et al. Autophagy suppresses tumor progression by limiting chromosomal instability. Genes Dev 2007; 21: 1367-1381.

29. Shimizu S, Kanaseki T, Mizushima N, Mizuta T, Arakawa-Kobayashi S, Thompson CB et al. Role of $\mathrm{Bcl}-2$ family proteins in a non-apoptotic programmed cell death dependent on autophagy genes. Nat Cell Biol 2004; 6: 1221-1228.

30. Yu L, Alva A, Su H, Dutt P, Freundt E, Welsh S et al. Regulation of an ATG7-beclin 1 program of autophagic cell death by caspase-8. Science 2004; 304: 1500-1502.

31. Klionsky DJ, Cuervo AM, Seglen PO. Methods for monitoring autophagy from yeast to human. Autophagy 2007; 3: 181-206.

32. Seagroves TN, Ryan HE, Lu H, Wouters BG, Knapp M, Thibault P et al. Transcription factor HIF-1 is a necessary mediator of the Pasteur effect in mammalian cells. Mol Cell Biol 2001; 21: $3436-3444$

33. Azad MB, Chen Y, Henson ES, Cizeau J, McMillan-Ward E, Israels SJ et al. Hypoxia induces autophagic cell death in apoptosis-competent cells through a mechanism involving BNIP3. Autophagy 2008; 4: 195-204.

34. Zhang H, Bosch-Marce M, Shimoda LA, Tan YS, Baek JH, Wesley JB et al. Mitochondrial autophagy is an HIF-1-dependent adaptive metabolic response to hypoxia. J Biol Chem 2008; 283: 10892-10903.

35. Bacon AL, Fox S, Turley H, Harris AL. Selective silencing of the hypoxia-inducible factor 1 target gene BNIP3 by histone deacetylation and methylation in colorectal cancer. Oncogene 2007; 26: 132-141.

36. Murai M, Toyota M, Suzuki H, Satoh A, Sasaki Y, Akino K et al. Aberrant methylation and silencing of the BNIP3 gene in colorectal and gastric cancer. Clin Cancer Res 2005; 11: 1021-1027.

37. Papandreou I, Cairns RA, Fontana L, Lim AL, Denko NC. HIF-1 mediates adaptation to hypoxia by actively downregulating mitochondrial oxygen consumption. Cell Metab 2006; 3: 187-197.

38. Yorimitsu T, Klionsky DJ. Endoplasmic reticulum stress: a new pathway to induce autophagy. Autophagy 2007; 3: 160-162.

39. Romero-Ramirez L, Cao H, Nelson D, Hammond E, Lee AH, Yoshida $\mathrm{H}$ et al. XBP1 is essential for survival under hypoxic conditions and is required for tumor growth. Cancer Res 2004; 64: 5943-5947.

40. Hosokawa N, Hara Y, Mizushima N. Generation of cell lines with tetracycline-regulated autophagy and a role for autophagy in controlling cell size. FEBS Lett 2006; 580: 2623-2629.

41. Paglin S, Hollister T, Delohery T, Hackett N, McMahill M, Sphicas E et al. A novel response of cancer cells to radiation involves autophagy and formation of acidic vesicles. Cancer Res 2001; 61: 439-444.

42. George MD, Baba M, Scott SV, Mizushima N, Garrison BS, Ohsumi $Y$ et al. Apg5p functions in the sequestration step in the cytoplasm-to-vacuole targeting and macroautophagy pathways. Mol Biol Cell 2000; 11: 969-982.

43. Gatenby RA, Gillies RJ. Why do cancers have high aerobic glycolysis? Nat Rev Cancer 2004; 4: 891-899.

44. Laderoute KR, Calaoagan JM, Gustafson-Brown C, Knapp AM, Li GC, Mendonca HL et al. The response of C-jun/AP-1 to chronic hypoxia is hypoxia-inducible factor 1 alpha dependent. Mol Cell Biol 2002; 22: 2515-2523.

\section{Supplementary Information accompanies the paper on Cell Death and Differentiation website (http://www.nature.com/cdd)}

